\title{
The impact of pharmacist face-to-face counseling to improve medication adherence among patients initiating statin therapy
}

This article was published in the following Dove Press journal:

Patient Preference and Adherence

10 April 2012

Number of times this article has been viewed

\section{Michael Taitel' \\ Jenny Jiang' \\ Kristi Rudkin ${ }^{2}$ \\ Susan Ewing ${ }^{2}$ \\ Ian Duncan'}

'Clinical Outcomes and Analytics, Walgreens, ${ }^{2}$ Corporate Innovation Team, Walgreens, Deerfield,

Illinois, USA
Correspondence: Michael Taitel I4I5 Lake Cook Rd, MS \#L444,

Deerfield, IL, USA 60015

Tel +l 8479648102

Fax + I 8473742669

Email michael.taitel@walgreens.com
Purpose: To evaluate the impact of a community-based pharmacist-led face-to-face counseling program on medication adherence for patients who were new to therapy (NTT) for statin medications.

Patients and methods: This retrospective cohort study evaluated a program that was implemented in 76 national community pharmacies located in the midwest USA. It consisted of two face-to-face patient counseling sessions with a pharmacist that addressed patient barriers to adherence. A group of 2056 NTT statin patients was identified between September 1, 2010 and October 31, 2010, and was followed for 12 months. The intervention group consisted of 586 patients, and the comparison group comprised 516 patients. Outcomes were measured using the continuous medication possession ratio (MPR), categorical MPR, and medication persistency.

Results: After adjusting for covariates, the intervention group had statistically greater MPR than the comparison group at every month measured. For example, at 12 months the intervention group had a MPR of $61.8 \%$ (CI, 54.5\%-69.2\%) and the comparison group had a MPR of $56.9 \%$ (CI, 49.5\%-64.3\%); this 4.9\% difference is significant $(P<0.01)$. The 12 month categorical MPR also showed significant differences between groups $\left(X^{2}=6.12, P<0.05\right) ; 40.9 \%$ of the intervention group and $33.7 \%$ of comparison group had a MPR greater than or equal to $80 \%$. Finally, the intervention group had significantly greater persistency with their medication therapy than the comparison group at $60,90,120$, and 365 days.

Conclusion: Patients who participated in brief face-to-face counseling sessions with a community pharmacist at the beginning of statin therapy demonstrated greater medication adherence and persistency than a comparison group. This brief targeted intervention at the initiation of maintenance drug therapy moderates the high risk of nonadherence and discontinuation; it helps patients establish a routine of daily self-medication and potentially improves their long-term clinical outcomes.

Keywords: community pharmacy, adherence, counseling, motivational interviewing, statins

\section{Introduction}

Nonadherence to medication therapy is a problem faced by many patients with chronic conditions. ${ }^{1,2}$ It is estimated that more than $25 \%$ of patients in the USA are nonadherent with their prescribed medications. ${ }^{3}$ With over 133 million Americans, almost half of adults, living with at least one chronic condition, this problem is costly in terms of morbidity, mortality and health care budgets. ${ }^{4-7}$ In 2009, the annual cost of nonadherence in the USA was estimated at USD\$290 billion. ${ }^{8}$

Hypercholesterolemia is one of the most common chronic conditions, affecting over 33.5 million adults in the USA, and it is a significant risk factor for 
cardiovascular disease. ${ }^{9,10}$ For some patients, it can be managed with improvements to diet and exercise; but for many others, additional medication therapy such as statin drugs, is required to lower cholesterol levels. ${ }^{11,12}$ Unfortunately, many patients are nonadherent to statin medications. ${ }^{9}$ It has been reported that medical costs and risk of hospitalization for patients with hypercholesterolemia whose medication adherence rates were less than $80 \%$, were significantly higher than for those with adherence rates of $80 \%$ and greater. ${ }^{7}$

Nonadherence may be driven by a myriad of factors that can be practical and behavioral. These factors include personal beliefs/environment, sociodemographic characteristics, disease state, comorbidities, health status, cost factors, patient perception of drug therapy value, issues related to drug regimen complexity and side effects, health literacy, and poor communication with health professionals. ${ }^{13-17}$ For example, a survey of patients with poor adherence to antihypertensive drug therapy in a managed care setting found that simple forgetfulness and being too busy were the most common reasons given for poor adherence. ${ }^{18}$

Community pharmacists are well positioned to help patients overcome barriers to adherence. Several studies demonstrate that patient counseling by community pharmacists can improve persistence, adherence, self-care, and in some cases yield a net economic return.,19-22 For example, Project ImPACT showed that for patients with poorly controlled lipid disorders, counseling by pharmacists in community pharmacy settings can improve persistence and adherence with drug therapy, and improve lipid levels. ${ }^{19}$ In the Asheville Program, a multi-year study involving consultation for diabetic patients with community-based pharmacists, glycosylated hemoglobin (A1C) values and lipid levels improved, medical costs decreased and worker productivity increased. ${ }^{20}$ The Ten City Challenge demonstrated that community pharmacist-provided diabetes patient coaching results in greater patient engagement in self-care and improved process of care indicators including A1C, influenza vaccinations, systolic and diastolic blood pressure, lipid profiles and percentage of patients receiving foot and eye examinations. ${ }^{21}$ Finally, a systematic review of the published literature found pharmacist face-to-face interventions performed in community pharmacy settings to be more effective than other types of interventions at improving patient adherence to medication therapy. ${ }^{22}$

The objective of the present study was to assess the impact of a community-based pharmacist-led face-to-face counseling program on medication adherence for patients who were new to therapy with statin medications.

\section{Methods}

We conducted a retrospective cohort study to evaluate a program designed to improve medication adherence and persistency among patients who were new to therapy (NTT) for statin medications. Patients were defined as NTT if the patient had no evidence of a filled prescription in the statin therapeutic class during the previous 15 months. The program was implemented in 76 national community pharmacies located in a major metropolitan area in the Midwest. The program consisted of two face-to-face patient counseling sessions with a clinical pharmacist.

All 214 licensed pharmacists providing interventions received 2 hours of additional training via an interactive webinar. The training focused on brief motivational interviewing techniques for addressing patient barriers to adherence. It also included practical techniques on how to fit the counseling sessions into their existing pharmacy workflow.

\section{Patient selection}

When a patient submitted a prescription for a statin medication and was identified by the pharmacy data system as NTT, the system notified the pharmacist to offer the patient a first fill face-to-face counseling session. The first session consisted of motivational interviewing to determine the patient's confidence and commitment to following the prescribed treatment regimen as well as discussion about fitting medications into their daily routine. Patients who completed the initial counseling session and who were not excluded due to self-report of prior use of statins were automatically eligible for a follow-up counseling session to be completed at their second fill. The pharmacy data system notified the pharmacist to offer a second counseling session that reinforced messages from the first session; the pharmacist inquired about the patient's experience during the first month of treatment and focused on removing any barriers to adherence. On average, the new to therapy conversation lasted 3 to 5 minutes, and follow-up conversations were 1 to 2 minutes in length.

Patients who filled their initial statin prescription and received both face-to-face first fill and second fill counseling sessions that were less than 6 months apart were included in the intervention group. Targeted NTT patients who filled their initial statin prescription during the study period but did not receive any face-to-face counseling were included in the comparison group. Comparison group patients did not receive consultations due to various reasons such as caregivers picking up the prescription, use of drive through prescription pick-up, or did not have time to wait for consultation during 
busy hours. In addition, to align with the criteria applied to the intervention group, patients in the comparison group were required to have at least two filled prescriptions and the first and second fill had to occur less than 6 months apart.

A group of 2056 patients who were NTT for statin medication between September 1, 2010 and October 31, 2010 were followed for 12 months after their initial identification date. Eligibility criteria included NTT patients who filled an initial 30-day quantity of statin medication. There was no quantity restriction for refills; so some patients may have refilled with 90-day quantities. As detailed in Figure 1, out of 2056 NTT patients, 702 patients did not receive any intervention, while 476 patients received a first fill intervention but were not eligible for a second fill intervention due to prior use of statin medication. After applying inclusion and exclusion criteria, the intervention group consisted of 586 patients and the comparison group included 516 patients. There were no statistically significant differences between the intervention and comparison groups in mean age, age bands, gender distribution, pharmaceutical benefit plan type, or co-pay amounts (Table 1). The average income level of patients, as determined by pharmacy trade area estimates, was not significantly different between groups (data not shown). Finally, there was no significant difference between the groups in comorbidities as measured by the number of unique therapeutic classes.

\section{Outcome measures}

Adherence was measured using the medication possession ratio (MPR), which was calculated by taking patients' total days' supply of statin medications during the observation period and dividing by total days during the observation period. ${ }^{23}$ Monthly MPR was calculated for an observation period starting with the initial fill and ending at the specified month; measurement continued until month 12. For overlapping prescriptions such as early refills, the start date of the refill was adjusted to the day after the prior prescription was exhausted. Similarly, if the due date of the last prescription was beyond the observational period, the due date of the last prescription was truncated to the end of the observational period. Additionally, a categorical MPR was used to compare the study groups at 365 days. We considered patients with an MPR of $80 \%$ or higher as adherent, and patients with an MPR less than $80 \%$ were nonadherent. The $80 \%$ threshold is commonly used to imply "adherent" in medication adherence research. ${ }^{23}$

Persistency is the duration in days from the initiation to discontinuation of statin therapy during the follow-up period. ${ }^{23}$

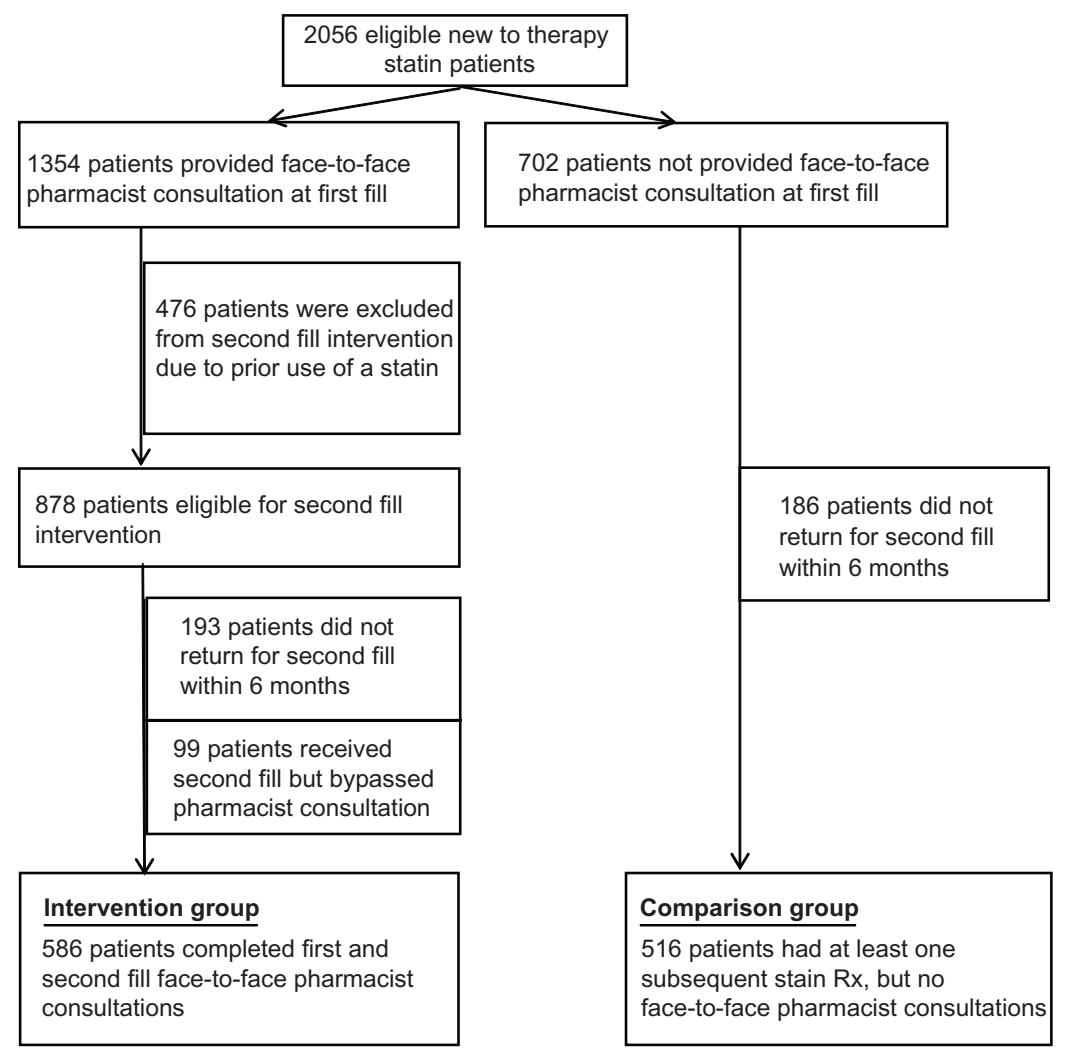

Figure I Patient selection. 
Table I Baseline characteristics of study groups

\begin{tabular}{|c|c|c|c|c|}
\hline & \multicolumn{2}{|c|}{$\begin{array}{l}\text { Intervention group } \\
(\mathbf{N}=586)\end{array}$} & \multicolumn{2}{|c|}{$\begin{array}{l}\text { Comparison group } \\
(N=5 \mid 6)\end{array}$} \\
\hline & Patients, $n$ & $\%$ & Patients, $\mathbf{n}$ & $\%$ \\
\hline \multicolumn{5}{|l|}{ Gender } \\
\hline Male & 271 & 46 & 255 & 49 \\
\hline Female & 315 & 54 & 261 & 51 \\
\hline \multicolumn{5}{|l|}{ Age, years } \\
\hline 18-34 & 37 & 6 & 19 & 4 \\
\hline $35-54$ & 256 & 44 & 216 & 42 \\
\hline $55-64$ & 172 & 29 & 165 & 32 \\
\hline $65+$ & $12 \mid$ & 21 & 116 & 22 \\
\hline Mean (SD) years & $54.2(12.4)$ & & $56.0(12.2)$ & \\
\hline \multicolumn{5}{|l|}{ Plan type } \\
\hline Commercial & $44 I$ & 75 & 378 & 73 \\
\hline Government & $|4|$ & 24 & 135 & 26 \\
\hline Cash & 4 & 1 & 3 & 1 \\
\hline \multicolumn{5}{|l|}{ Co-pay, USD } \\
\hline$\$ 0.00$ & 79 & 13 & 68 & 13 \\
\hline$\$ 0-10$ & 351 & 60 & 279 & 54 \\
\hline$\$ 10-20$ & 63 & II & 72 & 14 \\
\hline$\$ 20-30$ & 23 & 4 & 39 & 7 \\
\hline$>\$ 30$ & 70 & 12 & 58 & II \\
\hline
\end{tabular}

Therapeutic classes per patient

\begin{tabular}{lll} 
Mean (SD) & $3.24(1.99)$ & 3.21 \\
\hline Note: & $(1.96)$
\end{tabular}

Note: There were no significant differences between groups on any descriptive variable.

Abbreviation: SD, standard deviation.

We measured persistency as the percentage of patients who had any available statin medication at 60, 90, and 120 days using a 15-day permissive gap. We also measured persistency at 365 days using a 60-day permissive gap. Patients were considered discontinued if they did not have a refill within the permissive gap. In a review of the persistency literature, Sikka et al reported that permissive refill gaps range from 15 to 120 days, and there is little direction in the literature to determine the appropriate length of the gap. ${ }^{24}$ We used the shortest permissive gap in order to measure the early impact of the intervention; it essentially measures how quickly patients return to refill their medications. A larger permissive gap was also used to assess the long-term persistency to medications.

\section{Statistical analysis}

The association between patient adherence and pharmacist face-to-face counseling was evaluated with a multivariate linear regression model including covariates of age, gender, number of therapeutic classes, insurance plan type (cash, commercial, government), and prescription co-pay amount measured in USD $\$ 10$ bands between USD $\$ 0$ and USD \$30, and over USD \$30. The regression model was repeated using monthly MPR results from 2 to 12 cumulative months to determine the relationship between the study groups and medication adherence. Student's $t$-tests were calculated to determine the statistical significance of differences between unadjusted MPR group means. Chi-square tests were used to determine differences in proportions for categorical MPR and persistency. The $P$-value for statistical significance was set at $\alpha \leq 0.05$. All analyses were conducted using $\mathrm{SAS}^{\circledR}$ Software (v 9.2; SAS Institute Inc, Cary, NC).

\section{Results}

The unadjusted MPR for the intervention group was significantly greater than the comparison group at every month measured (Table 2).

After adjusting for covariates, the regression model also showed that the intervention group had significantly greater MPR than the comparison group at every monthly period measured (Table 3 and Figure 2). Over time, both groups had decreasing MPR, however, the intervention group declined at a slower rate during most months. At the end of 12 months, the intervention group had an MPR of $61.8 \%$ and the comparison group had an MPR of $56.9 \%$; this was an absolute difference

Table 2 Unadjusted medication possession ratio by study group and month

\begin{tabular}{|c|c|c|c|c|c|}
\hline $\begin{array}{l}\text { Follow-up } \\
\text { period }\end{array}$ & $\begin{array}{l}\text { Intervention group, \% } \\
(95 \% \mathrm{Cl})(\mathbf{N}=\mathbf{5 8 6})\end{array}$ & $\begin{array}{l}\text { Comparison group, \% } \\
(95 \% \mathrm{Cl})(\mathrm{N}=5 \mathrm{I})\end{array}$ & $\begin{array}{l}\text { Absolute } \\
\text { difference, \% }\end{array}$ & $\begin{array}{l}\text { Relative } \\
\text { difference, \% }\end{array}$ & $P$ value \\
\hline 2-month & $87.6(86.1-89.0)$ & $84.8(83.2-86.4)$ & 2.8 & 3.3 & $<0.05$ \\
\hline 3-month & $83.0(81.5-84.6)$ & $80.2(78.5-81.9)$ & 2.8 & 3.5 & $<0.05$ \\
\hline 4-month & $79.4(77.7-81.0)$ & $75.8(74.0-7.70)$ & 3.5 & 4.6 & $<0.01$ \\
\hline 5-month & $76.5(74.7-78.2)$ & 73.2 (7I.3-75.I) & 3.3 & 4.5 & $<0.05$ \\
\hline 6-month & $74.2(72.4-76.1)$ & 70.7 (68.7-72.7) & 3.5 & 4.9 & $<0.05$ \\
\hline 7-month & 72.1 (70.2-73.9) & $68.4(66.3-70.5)$ & 3.7 & 5.4 & $<0.05$ \\
\hline 8-month & $70.3(68.3-72.3)$ & $66.3(64.1-68.6)$ & 3.9 & 6.0 & $<0.01$ \\
\hline 9-month & $68.4(66.3-70.4)$ & $64.4(62.1-66.7)$ & 3.9 & 6.2 & $<0.05$ \\
\hline I0-month & $66.7(64.6-68.9)$ & $62.6(60.2-65.0)$ & 4.0 & 6.5 & $<0.05$ \\
\hline II-month & $65.2(63.0-67.4)$ & $60.8(58.4-63.2)$ & 4.4 & 7.2 & $<0.01$ \\
\hline I2-month & $63.5(61.2-65.8)$ & $58.9(56.5-61.4)$ & 4.4 & 7.5 & $<0.01$ \\
\hline
\end{tabular}

Abbreviation: $\mathrm{Cl}$, confidence interval. 
Table 3 Adjusted medication possession ratio (MPR) by study group and month ${ }^{\dagger}$

\begin{tabular}{|c|c|c|c|c|c|}
\hline $\begin{array}{l}\text { Follow-up } \\
\text { period }\end{array}$ & $\begin{array}{l}\text { Intervention group, \% } \\
(95 \% \mathrm{CI})(\mathrm{N}=586)\end{array}$ & $\begin{array}{l}\text { Comparison group, \% } \\
(95 \% \mathrm{CI})(\mathrm{N}=5 \mathrm{I} / 6)\end{array}$ & $\begin{array}{l}\text { Absolute } \\
\text { difference, \% }\end{array}$ & $\begin{array}{l}\text { Relative } \\
\text { difference, \% }\end{array}$ & $P$-value \\
\hline 2-month & $86.4(8|.7-9| . \mid)$ & $83.6(78.9-88.3)$ & 2.8 & 3.3 & $<0.01$ \\
\hline 3-month & $82.3(77.3-87.4)$ & $79.5(74.5-84.6)$ & 2.8 & 3.5 & $<0.05$ \\
\hline 4-month & 78.3 (72.8-83.7) & $74.7(69.2-80.1)$ & 3.6 & 4.8 & $<0.01$ \\
\hline 5-month & $75.3(69.7-81.0)$ & $71.9(66.3-77.6)$ & 3.4 & 4.7 & $<0.01$ \\
\hline 6-month & $74.7(68.8-80.7)$ & $71.0(65.0-77.0)$ & 3.7 & 5.2 & $<0.01$ \\
\hline 7-month & $72.2(65.9-78.5)$ & $68.3(62.0-74.6)$ & 3.9 & 5.7 & $<0.01$ \\
\hline 8-month & $70.0(63.5-76.6)$ & $65.7(59.2-72.3)$ & 4.3 & 6.5 & $<0.01$ \\
\hline 9-month & $67.7(60.9-74.5)$ & $63.4(56.6-70.2)$ & 4.3 & 6.8 & $<0.01$ \\
\hline I0-month & $65.8(58.8-72.8)$ & $61.4(54.3-68.4)$ & 4.4 & 7.2 & $<0.01$ \\
\hline II-month & 64.1 (56.9-7I.3) & $59.3(52.1-66.5)$ & 4.8 & 8.1 & $<0.01$ \\
\hline I2-month & $61.8(54.5-69.2)$ & $56.9(49.5-64.3)$ & 4.9 & 8.6 & $<0.01$ \\
\hline
\end{tabular}

Note: ${ }^{\dagger}$ Adjusted MPR based on age, gender, payer type, co-pay amount, and number of therapeutic classes. Abbreviation: $\mathrm{Cl}$, confidence interval.

of $4.9 \%$ and a relative difference of $8.6 \%$ (intervention group MPR/comparison group MPR) $(P<0.01)$.

The categorical MPR showed that the intervention group had a significantly higher proportion of adherent patients $(\mathrm{MPR} \geq 80 \%$ ) than the comparison group. At 12 months, $40.9 \%$ of the intervention group and $33.7 \%$ of the comparison group were adherent. The $7.2 \%$ difference between the groups was significant $\left(X^{2}=6.12, P<0.05\right)$.

The intervention group had greater initial persistency to their medication therapy than the comparison group (Table 4). Using a 15-day permissive gap, $79.5 \%$ of patients in the intervention group and $74.0 \%$ of patients in the comparison group were persistent at 60 days $\left(X^{2}=4.66, P<0.05\right)$. Using a 60 -day permissive gap, $43.9 \%$ of patients in the intervention group and $38.2 \%$ of patients in the comparison group were persistent at 365 days $\left(X^{2}=3.65, P=0.05\right)$.

\section{Discussion}

Patients who participated in community pharmacist faceto-face counseling sessions at the beginning of statin therapy demonstrate greater adherence and persistence to their medication therapy than a usual care comparison group. The pharmacists used motivational interviewing techniques in their counseling to help patients get a good start on their new medication. This method allowed patients to articulate their confidence and commitment to their new therapy and to address any perceived barriers to good adherence. In addition, the counseling helped patients learn to fit the medication into their daily routine. The initial gains in adherence, seen immediately after the counseling sessions, continued for 12 months. Over time, both groups had decreasing MPR, however the intervention group declined at a slower rate. The measure of persistency using

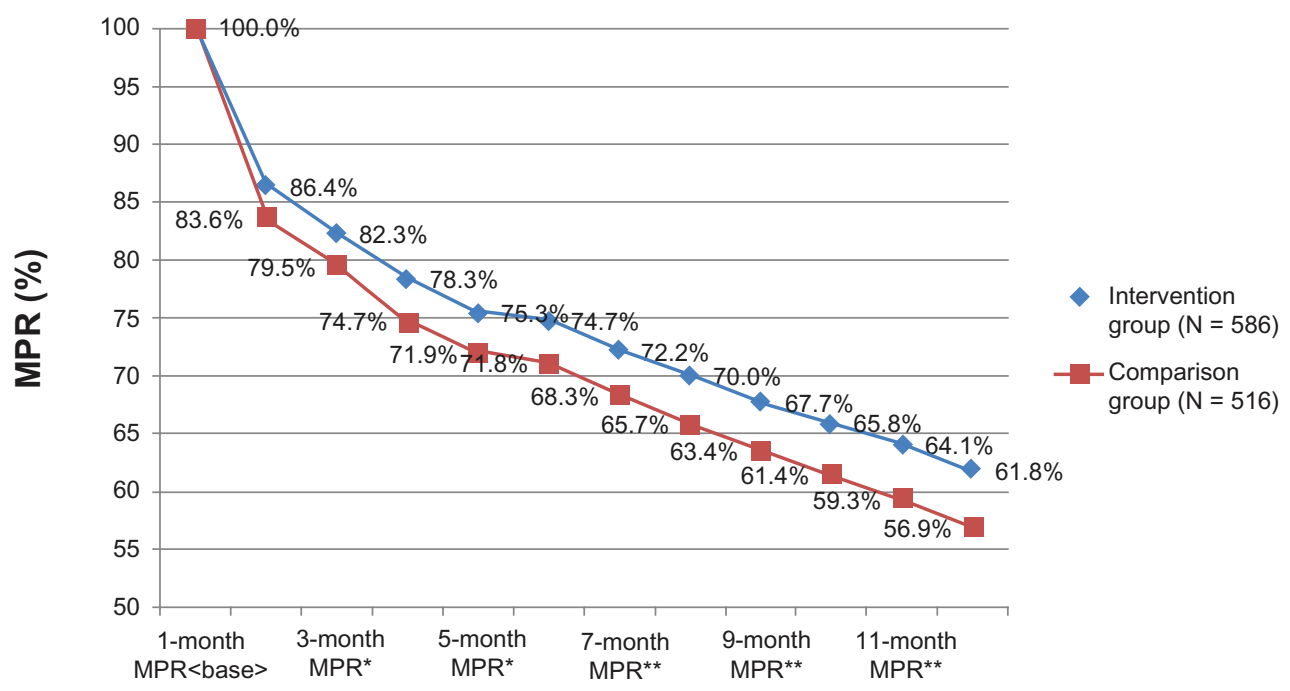

Figure 2 Adjusted ${ }^{\dagger}$ medication possession ratio (MPR) by study group and month.

Notes: ${ }^{\dagger}$ Adjusted MPR based on age, gender, payer type, co-pay amount, and number of therapeutic classes. $* P<0.05 ; * * P<0.01$. 
Table 4 Medication persistency between study groups

\begin{tabular}{|c|c|c|c|c|c|c|}
\hline \multirow[t]{2}{*}{ Persistency } & \multicolumn{2}{|l|}{$\%$ of patients persistent } & \multirow[t]{2}{*}{ Absolute difference, \% } & \multirow[t]{2}{*}{ Relative difference, \% } & \multirow[t]{2}{*}{$x^{2}$} & \multirow[t]{2}{*}{$P$-value } \\
\hline & Intervention group, \% & Comparison group, \% & & & & \\
\hline 60-day & 79.5 & 74.0 & 5.5 & 7.4 & 4.66 & $<0.05$ \\
\hline 90-day & 64.0 & 56.6 & 7.4 & 13.1 & 6.29 & $<0.05$ \\
\hline 120-day & 52.7 & 46.3 & 6.4 & 13.8 & 4.51 & $<0.05$ \\
\hline 365-day ${ }^{\dagger}$ & 43.9 & 38.2 & 5.7 & 14.9 & 3.65 & 0.05 \\
\hline
\end{tabular}

Note: Use of a 60-day permissive gap, otherwise 15-day permissive gap.

a relatively short permissive gap of 15 days showed that patients in the intervention group refilled their prescriptions more quickly than the comparison group. However, the short permissive gap was too restrictive to measure the true persistency over time because it removes data for patients who are still on therapy but late to refill their medications. When we used a 60-day permissive gap, the groups were marginally, but significantly different at the end of 12 months. Together these results show that the intervention had positive impact, however additional interventions may be needed, beyond the initial consultations, to reinforce the positive behavior change seen in the intervention group. While not measured in this study, improved adherence to statin therapy should lead to reductions in lipid levels and ultimately reductions in morbidity, mortality, and health care costs. $^{7}$

These findings are similar to other studies demonstrating the impact of pharmacist interventions to improve medication adherence. ${ }^{19,25,26}$ Cutrona et al conducted a systematic review of randomized studies of various methods to improve medication adherence to a range of cardiovascular medications..$^{22}$ They report that 5 out of 6 studies that measured comprehensive pharmacist interventions that included multiple session, blister packaging, and other tools, significantly improved medication adherence between $7 \%-27 \%$.

The present study measured the impact of two brief counseling sessions on patients new to therapy for statin medications. Additional research is needed to independently validate these findings and determine whether they generalize to other therapeutic classes and chronic conditions. Furthermore, a multi-armed, randomized study design is recommended to compare the effectiveness of various adherence interventions and control for potential biases.

\section{Limitations}

This analysis utilized data from a single pharmacy chain and did not include data from other pharmacies. Furthermore, as with all studies using pharmacy claims data and MPR to determine adherence; it is not possible to determine whether the medications were actually taken as prescribed. Patients in the intervention group were counseled by different pharmacists at different stores; therefore, there was some uncontrolled variation in the intervention. Patients essentially self-selected into either the intervention or comparison group, which may have introduced some uncontrolled bias. However, the fact that the demographics and utilization characteristics of both groups are similar provides some assurance that the baseline group differences are minimal. Furthermore, we used a multivariate linear regression model including covariates of age, gender, number of therapeutic classes, insurance plan type, and prescription co-pay amount to minimize potential bias.

\section{Conclusion}

Patients who participated in brief face-to-face counseling sessions with a community pharmacist at the beginning of statin therapy demonstrate greater medication adherence and persistency than a comparison group. This brief intervention at the initiation of maintenance drug therapy moderates the high risk of nonadherence and discontinuation; it helps patients establish a routine of daily self-medication and potentially improves their long-term clinical outcomes.

\section{Acknowledgments}

The authors wish to acknowledge Janeen DuChane, Nikhil Khandelwal, Elan Rubenstein and Rachel O'Koren for their help developing the manuscript. This study was sponsored by Walgreen Co. All contributors were employees of Walgreen Co and Elan Rubinstein is a consultant to Walgreen Co.

\section{Disclosure}

The authors report no financial relationship other than that outlined in the Acknowledgments or other potential conflicts of interest related to the subject of this manuscript. $\mathrm{KR}$, JJ, and MT designed the study methodology; JJ and MT conducted the analysis; MT, JJ, ER, and RO wrote sections of the manuscript; and KR, SE, JD, and ID provided editorial review. 


\section{References}

1. Sabaté E. Adherence to Long-term Therapies: Evidence for Action. Geneva: World Health Organization; 2003. Available from: http:// whqlibdoc.who.int/publications/2003/9241545992.pdf. Accessed March 1, 2012.

2. Yeaw J, Benner JS, Walt JG, Sian S, Smith DB. Comparing adherence and persistence across 6 chronic medication classes. J Manag Care Pharm. 2009;15(9):724-736.

3. Thier SL, Yu-Isenberg KS, Leas BF, et al. In chronic disease, nationwide data show poor adherence by patients to medication and by physicians to guidelines. Manag Care. 2008;17(2):48-52.

4. National Center for Chronic Disease Prevention and Health Promotion. Chronic Diseases: The Power to Prevent, the Call to Control. National Center for Chronic Disease Prevention and Health Promotion; 2009. Available from: http://www.cdc.gov/chronicdisease/resources/ publications/AAG/chronic.htm. Accessed March 1, 2012.

5. Ho PM, Rumsfeld JS, Masoudi FA, et al. Effect of medication nonadherence on hospitalization and mortality among patients with diabetes mellitus. Arch Intern Med. 2006;166(17):1836-1841.

6. Ho PM, Magid DJ, Masoudi FA, McClure DL, Rumsfeld JS. Adherence to cardioprotective medications and mortality among patients with diabetes and ischemic heart disease. BMC Cardiovasc Disord. 2006;6:48.

7. Sokol MC, McGuigan KA, Verbrugge RR, Epstein RS. Impact of medication adherence on hospitalization risk and healthcare cost. Med Care. 2005;43(6):521-530.

8. New England Healthcare Institute. Thinking Outside the Pillbox: A System-wide Approach to Improving Patient Medication Adherence for Chronic Disease. Cambridge, MA: New England Healthcare Institute; 2009. Available from: http://www.nehi.net/uploads/full_report/ pa_issue_brief_final.pdf. Accessed March 1, 2012

9. Roger VL, Go AS, Lloyd-Jones DM, et al. Heart disease and stroke statistics - 2011 update: a report from the American Heart Association. Circulation. 2011;123(4):e18-e209.

10. Keevil JG, Cullen MW, Gangnon R, McBride PE, Stein JH. Implications of cardiac risk and low-density lipoprotein cholesterol distributions in the United States for the diagnosis and treatment of dyslipidemia: data from National Health and Nutrition Examination Survey 1999 to 2002. Circulation. 2007;115(11):1363-1370.

11. Cholesterol Treatment Trialists Collaborators, Kearney PM, Blackwell L, et al. Efficacy of cholesterol-lowering therapy in 18,686 people with diabetes in 14 randomised trials of statins: a meta-analysis. Lancet. 2008;371(9607):117-125.

12. Preiss D, Sattar N. Lipids, lipid modifying agents and cardiovascular risk: a review of the evidence. Clin Endocrinol (Oxf). 2009;70(6): 815-828.
13. Krousel-Wood MA, Muntner P, Islam T, Morisky DE, Webber LS Barriers to and determinants of medication adherence in hypertension management: perspective of the cohort study of medication adherence among older adults. Med Clin North Am. 2009;93(3):753-769.

14. Osterberg L, Blaschke T. Adherence to Medication. $N$ Engl J Med. 2005;353(5):487-497.

15. Chernew M, Gibson TB, Yu-Isenberg K, Sokol MC, Rosen AB, Fendrick AM. Effects of increased patient cost sharing on socioeconomic disparities in health care. J Gen Intern Med. 2008;23(8):1131-1136.

16. Pedan A, Varasteh L, Schneeweiss S. Analysis of factors associated with statin adherence in a hierarchical model considering physician, pharmacy, patient, and prescription characteristics. J Manag Care Pharm. 2007;13(6):487-496.

17. Gellad WF, Grenard J, McGlynn EA. A Review of Barriers to Medication Adherence: A Framework for Driving Policy Options. Santa Monica, CA: RAND Health; 2009.

18. Nair KV, Belletti DA, Doyle JJ, et al. Understanding barriers to medication adherence in the hypertensive population by evaluating responses to a telephone survey. Patient Prefer Adherence. 2011;5: 195-206.

19. Bluml BM, McKenney JM, Cziraky MJ. Pharmaceutical care services and results in project ImPACT: hyperlipidemia. J Am Pharm Assoc (Wash). 2000;40(2):157-165.

20. Bunting BA, Smith BH, Sutherland SE. The Asheville Project: clinical and economic outcomes of a community-based long-term medication therapy management program for hypertension and dyslipidemia. J Am Pharm Assoc. 2008;48(1):23-31.

21. Fera T, Bluml BM, Ellis WM. Diabetes Ten City Challenge: final economic and clinical results. J Am Pharm Assoc. 2009;49(3):383-391.

22. Cutrona SL, Choudhry NK, Fischer MA, et al. Modes of delivery for interventions to improve cardiovascular medication adherence: Review. Am J Manag Care. 2010;16(12):929-942.

23. Cramer JA, Roy A, Burrell A, et al. Medication compliance and persistence: terminology and definitions. Value Health. 2008;11(1): 44- 47.

24. Sikka R, Xia F, Aubert RE. Estimating medication persistency using administrative claims data. Am J Manag Care. 2005;11(7):449-457.

25. Kripalani S, Yao X, Haynes RB. Interventions to enhance medication adherence in chronic medical conditions: a systematic review. Arch Intern Med. 2007;167(6):540-550.

26. Lee JK, Grace KA, Taylor AJ. Effect of a pharmacy care program on medication adherence and persistence, blood pressure, and lowdensity lipoprotein cholesterol: a randomized controlled trial. JAMA. 2006;296(21):2563-2571.
Patient Preference and Adherence

\section{Publish your work in this journal}

Patient Preference and Adherence is an international, peer-reviewed, open access journal focusing on the growing importance of patient preference and adherence throughout the therapeutic continuum. Patient satisfaction, acceptability, quality of life, compliance, persistence and their role in developing new therapeutic modalities and compounds to

\section{Dovepress}

optimize clinical outcomes for existing disease states are major areas of interest. This journal has been accepted for indexing on PubMed Central. The manuscript management system is completely online and includes a very quick and fair peer-review system. Visit http://www.dovepress.com/ testimonials.php to read real quotes from published authors. 